\title{
Reproducibility of Lymphocyte-To-Monocyte Ratio (LMR), Neutrophil-To-Lymphocyte Ratio (NLR) and Platelet-To-Lymphocyte Ratio (PLR) in Patients with Locally Advanced Rectal Cancer
}

Cieszymierz Gawiński ( $\nabla$ cieszymierzgawinski@gmail.com )

Maria Skłodowska-Curie Memorial Cancer Center and Institute of Oncology

Wojciech Michalski

Maria Skłodowska-Curie Memorial Cancer Center and Institute of Oncology

Lucjan Wyrwicz

Maria Skłodowska-Curie Memorial Cancer Center and Institute of Oncology

\section{Research Article}

Keywords: SIR marker, LMR, NLR, PLR, reproducibility, rectal cancer

Posted Date: January 21st, 2022

DOI: https://doi.org/10.21203/rs.3.rs-1243808/v1

License: (c) (i) This work is licensed under a Creative Commons Attribution 4.0 International License.

Read Full License

Version of Record: A version of this preprint was published at Journal of Clinical Oncology on February 1st, 2022. See the published version at https://doi.org/10.1200/JC0.2022.40.4_suppl.166. 


\section{Abstract}

Rectal cancer constitutes over one-third of all colorectal cancers (CRC) and is one of the leading cause of cancer-related death in developed countries. Treatment modalities applied in locally advanced tumors differ substantially among research centers. In order to identify high-risk patients and better adjust the therapy new markers are needed. Systemic inflammatory response (SIR) markers such as LMR, NLR and PLR have been proved highly prognostic in many malignancies, including CRC; however, they lack proper validation. In our study we assessed the reproducibility of LMR, NLR and PLR. Sixty patients with locally advanced rectal cancer treated in Maria-Sklodowska Curie National Research Institute of Oncology in Warsaw, Poland between 08.2017 and 12.2020 were prospectively enrolled in the study. Three consecutive blood morphology tests of each patient within a median period of 21 days were obtained before start of the treatment.

LMR, NLR and PLR calculated at two time-points were correlated with the coefficient of $0.776,0.696$ and 0.751 ( $p<0.005$ in all measurements), respectively. Cohen's Kappa statistic for the extent of agreement between the 1st and the 2nd measurement for LMR was $\mathrm{K}=0.59(95 \% \mathrm{Cl}, 0.39-0.79), \mathrm{p}<0.001$. For NLR the Kappa was $\mathrm{K}=0.45(95 \% \mathrm{Cl}, 0.22-0.68), \mathrm{p}<0.001$ and for PLR $\mathrm{K}=0.53(95 \% \mathrm{Cl}, 0.32-0.75$. Mean percentage change between the third and the first measurement of lymphocytes, monocytes, neutrophils and platelets count ranged from $-5.59-4.76 \%$ and the standard error from 2.0 to 3.9 .

In conclusion, SIR markers are moderately reproducible, easily obtained biomarkers with potential application in clinical practice.

\section{Introduction}

Rectal cancer constitutes around 35\% of all colorectal cancers (CRC) and its incidence in the European Union is estimated at 125000 per year. Due to sociodemographic changes and population ageing this figure is predicted to rise causing a growing problem for public health care. Despite significant progress in recent years prognosis, especially in advanced stages of the disease, remains unsatisfactory. The Union for International Cancer Control (UICC) tumor node metastasis (TNM) staging system, histological grade, tumor location, MRI-derived radiological findings, distance from the tumor to the mesorectal fascia are main prognostic factors essential for treatment planning [1, 2]. The current standard of care for patients with locally advanced rectal cancer (LARC) is neoadjuvant radiotherapy/chemo-radiotherapy followed by surgery according to total mesorectal excision (TME) principles and postoperative chemotherapy. The novel approach of total neoadjuvant therapy (TNT) consists in incorporating all chemotherapy in the neoadjuvant setting [3]. There are considerable differences in terms of treatment modalities applied in patients with LARC among countries and research centers. It is crucial to appropriately identify high-risk patients to optimize the therapy. In order to avoid both under- and over-treatment new, easily accessible and reliable markers are needed. In recent years, a strong prognostic value of blood-based systemic inflammatory response (SIR) biomarkers such as LMR, NLR and PLR has become well-proven in many malignancies [4-6]. SIR markers have been thoroughly investigated in CRC. High NLR, high PLR and low 
LMR are predictors of unfavorable prognosis - it applies to both overall survival (OS) and disease-free survival (DFS)/recurrence-free survival (RFS) [7-9]. In order to implement SIR markers into risk assessment protocols and use them for stratifying the prognosis in clinical practice their reliability needs to be determined.

In our study, we evaluated the pre-treatment reproducibility of LMR, NLR and PLR measurements in patients with LARC in order to assess the possibility of their use in the treatment allocation process.

\section{Materials And Methods}

A single-arm prospective study among patients treated in Maria Skłodowska-Curie National Research Institute of Oncology in Warsaw was conducted. The eligibility criteria were as followed: 1) patients were diagnosed with primary locally advanced rectal cancer confirmed by histopathology; 2) clinical records including demographic data and laboratory data were available and complete; 3 ) patients were $>18$ years old. The exclusion criteria were: 1) presence of distant metastasis at the time of diagnosis; 2) patients received neoadjuvant chemo- and/or radiotherapy 3) presence of malignant tumors in other organs; 4) presence of hematological malignancies, acute or chronic inflammatory diseases and other medical conditions that could affect inflammatory markers; 5 ) prior immunosuppressive therapy. Blood samples from patients were obtained three times within a median period of 21 days (range, 7-55 days). All the tests were performed prior to any oncological treatment. The differential white blood cell count was analyzed using the Sysmex XN-550 hematology analyzer following the manufacturer protocol. LMR, NLR and PLR were calculated from the blood samples by dividing an absolute lymphocyte count by an absolute monocyte count, an absolute neutrophil count by an absolute lymphocyte count and an absolute platelet count by an absolute lymphocyte count, respectively. Patients were divided in terms of baseline values of SIR markers into LMR,NLR,PLR-high and low groups. The cut-off values were determined based on our previous studies and data available in the literature $[4,6,10,11]$.

Formulas:

LMR - absolute lymphocyte count $(\mathrm{g} / \mathrm{l})^{1} /$ absolute monocyte count $(\mathrm{g} / \mathrm{l})$

NLR - absolute neutrophil count $(\mathrm{g} / \mathrm{l})$ / absolute lymphocyte count $(\mathrm{g} / \mathrm{l})$

PLR - absolute platelet count (g/l) / absolute lymphocyte count (g/l)

${ }^{1}$ gram per liter

\section{Statistical analysis}

The Shapiro-Wilk test was used to test the normality of data distribution. The analysis of repeatability of measurements of SIR markers was evaluated using the Friedman's test. Binomial variables were compared between measurements with McNemar test. Additionally, confidence intervals for proportion 
were calculated, using binomial exact calculation. Cohen's Kappa was calculated to assess the extent of agreement between the 1 st and the 2 nd measurement, including $95 \%$ confidence interval. The relationship between parameters was assessed by Pearson's correlation analysis. Statistical analyses were performed using the IBM SPSS Statistics ver. 23 software package and R software, version 4.0.5.

\section{Ethical considerations}

The study conformed to the provisions of the Declaration of Helsinki and was approved by the ethics committee of National Institute of Oncology. All patients were informed of the investigational nature of this study and provided written informed consent.

\section{Results}

A total of 60 patients with rectal cancer treated in Maria Skłodowska-Curie National Research Institute of Oncology in Warsaw between 08.2017 and 12.2020 were prospectively enrolled in the study. Forty-three males and seventeen females were included. The median age was 66.5 years (range, 29-89 years old). Distribution of cancer stages were as followed: stage II-IIIA - 8 (13\%), stage IIIB - 41 (68\%) and stage IIIC - 10 (17\%). Stage of one of the patients remained undefined. There were no stages I or IV. Characteristics of patients is presented in table 1 .

Table 1. Characteristics 
All patients $(n=60)$

Age (years), median (range) 66.5 (29-89)

Sex, n (\%)

Male
Female
Tumor, $\mathbf{n}(\%)$

$\begin{array}{ll}\text { T3 } & 55(91.7) \\ \text { T4 } & 5(8.3)\end{array}$

Lymph nodes, $\mathrm{n}(\%)$

\begin{tabular}{ll} 
No & $8(13.3)$ \\
\hline N1 & $35(58.3)$ \\
\hline N2 & $16(26.7)$ \\
\hline Nx & $1(1.7)$ \\
\hline
\end{tabular}

\section{Grade, $\mathrm{n}(\%)$}

\begin{tabular}{ll} 
G1 & $2(3.3)$ \\
\hline$G 2$ & $42(70)$ \\
\hline$G 3$ & $2(3.3)$ \\
\hline$G x$ & $14(23.3)$ \\
\hline
\end{tabular}

\begin{tabular}{ll} 
Stage, $\mathbf{n}(\%)$ & \\
\hline II-IIIA & $8(13.3)$ \\
IIIB & $41(68.3)$ \\
IIIC & $10(16.7)$
\end{tabular}

Time between measurements

(days), median (range)

\begin{tabular}{ll} 
1st-2nd & $9(1-42)$ \\
\hline 2nd-3rd & $11(1-34)$ \\
\hline 1st-3rd & $21(7-55)$
\end{tabular}


The median value of LMR in three consecutive measurements was 2.71 (range 1.11-6.42), 2.93 (0.247.32) and 2.8 (0.87-6.98) $(\mathrm{p}=0.766)$. Median value of NLR was $2.71(1.17-7.58), 2.84(0.81-8.96)$ and 2.47 (1.04-10.22) respectively $(p=0.344)$. Medians of PLR were 150 (67-551), 141 (54-479) and 141 (67430) $(p=0.627)$. All median and mean values of lymphocyte, monocyte, neutrophil and platelet count as well as their ratios are shown in table 2. The results of three measurements of LMR, NLR and PLR are illustrated in appendix fig.1.

Table 2. Median values of measurements

\begin{tabular}{|c|c|c|c|c|c|}
\hline$x$ & $\begin{array}{l}1^{\text {st }} \\
\text { measurement }\end{array}$ & $2^{\text {nd }}$ measurement & $\begin{array}{l}3^{\text {rd }} \\
\text { measurement }\end{array}$ & $\begin{array}{l}\text { All } \\
\text { measurements } \\
\text { (mean) }\end{array}$ & $\begin{array}{l}\mathrm{p} \\
\text { value }^{1}\end{array}$ \\
\hline $\begin{array}{l}\operatorname{ALC}\left(10^{\wedge} 9 / 1\right) \\
\text { median (range) }\end{array}$ & $\begin{array}{l}1.72(0.70- \\
3.79)\end{array}$ & $1.65(0.69-4.02)$ & $\begin{array}{l}1.67(0.52- \\
3.92)\end{array}$ & $\begin{array}{l}1.67(0.52- \\
4.02)\end{array}$ & 0.541 \\
\hline $\begin{array}{l}\operatorname{ALC}\left(10^{\wedge} 9 / 1\right) \\
\text { mean }(S D)\end{array}$ & $1.84(0.69)$ & $1.87(0.76)$ & $1.86(0.73)$ & $1.86(0.69)$ & \\
\hline $\begin{array}{l}\text { AMC }\left(10^{\wedge} 9 / \mathrm{I}\right) \\
\text { median (range) }\end{array}$ & $\begin{array}{l}0.61(0.30- \\
1.30)\end{array}$ & $0.64(0.27-5.26)$ & $\begin{array}{l}0.64(0.33- \\
1.21)\end{array}$ & $\begin{array}{l}0.63(0.27- \\
5.26)\end{array}$ & 0.800 \\
\hline $\begin{array}{l}\text { AMC }\left(10^{\wedge} 9 / \mathrm{I}\right) \\
\text { mean }(\mathrm{SD})\end{array}$ & $0.68(0.25)$ & $0.77(0.65)$ & $0.68(0.24)$ & $0.71(0.30)$ & \\
\hline $\begin{array}{l}\text { ANC }\left(10^{\wedge} 9 / \mathrm{I}\right) \\
\text { median (range) }\end{array}$ & $\begin{array}{l}4.89(2.42- \\
12.36)\end{array}$ & $5.10(2.11-12.27)$ & $\begin{array}{l}4.43(2.35- \\
13.69)\end{array}$ & $\begin{array}{l}4.84(2.11- \\
13.69)\end{array}$ & 0.770 \\
\hline $\begin{array}{l}\text { ANC }\left(10^{\wedge} 9 / \mathrm{I}\right) \\
\text { mean }(\mathrm{SD})\end{array}$ & $5.43(2.05)$ & $5.26(2.00)$ & $5.02(2.03)$ & $5.24(1.91)$ & \\
\hline $\begin{array}{l}\text { Platelets }\left(10^{\wedge} 9 / I\right) \text {, } \\
\text { median (range) }\end{array}$ & $\begin{array}{l}273.00 \\
(116.00- \\
666.00)\end{array}$ & $\begin{array}{l}254.00(149.00- \\
607.00)\end{array}$ & $\begin{array}{l}269.00 \\
(152.00- \\
601.00)\end{array}$ & $\begin{array}{l}264.00 \\
(116.00- \\
666.00)\end{array}$ & 0.198 \\
\hline $\begin{array}{l}\text { Platelets }\left(10^{\wedge} 9 / \mathrm{I}\right) \\
\text { mean }(\mathrm{SD})\end{array}$ & $\begin{array}{l}293.00 \\
(109.60)\end{array}$ & $284.00(94.12)$ & $\begin{array}{l}291.00 \\
(101.82)\end{array}$ & 289.00 (99.16) & \\
\hline $\begin{array}{l}\text { LMR, median } \\
\text { (range) }\end{array}$ & $\begin{array}{l}2.71(1.11- \\
6.42)\end{array}$ & $2.95(0.24-7.32)$ & $\begin{array}{l}2.8(0.87- \\
6.98)\end{array}$ & $\begin{array}{l}2.89(0.24- \\
7.32)\end{array}$ & 0.766 \\
\hline LMR, mean (SD) & $2.94(1.22)$ & $2.93(1.25)$ & $2.91(1.18)$ & $2.93(1.11)$ & \\
\hline $\begin{array}{l}\text { NLR, median } \\
\text { (range) }\end{array}$ & $\begin{array}{l}2.71(1.17- \\
7.58)\end{array}$ & $2.84(0.81-8.96)$ & $\begin{array}{l}2.47(1.04- \\
10.22)\end{array}$ & $\begin{array}{l}2.65(0.81- \\
10.22)\end{array}$ & 0.344 \\
\hline NLR, mean (SD) & $3.25(1.47)$ & $3.13(1.56)$ & $3.10(1.80)$ & $3.16(1.47)$ & \\
\hline $\begin{array}{l}\text { PLR, median } \\
\text { (range) }\end{array}$ & $\begin{array}{l}150.00 \\
(67.00- \\
551.00)\end{array}$ & $\begin{array}{l}141.00(54.00- \\
479.00)\end{array}$ & $\begin{array}{l}141.00 \\
(67.00- \\
430.00)\end{array}$ & $\begin{array}{l}142.00(54.00- \\
551.00)\end{array}$ & 0.627 \\
\hline PLR, mean (SD) & $\begin{array}{l}179.00 \\
(95.69)\end{array}$ & 173.00 (91.15) & $\begin{array}{l}180.00 \\
(95.01)\end{array}$ & 177.00 (87.90) & \\
\hline
\end{tabular}


${ }^{1} \mathrm{p}$ value calculated using the Friedman's test

Patients were divided into high and low groups according to baseline value of each SIR marker. The predetermined cut-offs were 2.6 for LMR, 3.0 for NLR and 150 for PLR. The number of patients who belonged to each group in each measurement is presented in table 3 .

Table 3. LMR,NLR, PLR-high/low patients in each measurement. 


\begin{tabular}{|c|c|c|c|c|c|c|c|c|}
\hline \multicolumn{6}{|c|}{ Measurement } & \multicolumn{3}{|l|}{$p^{1}$} \\
\hline $1^{\text {st }}$ & & $2^{\text {nd }}$ & & $3^{\text {rd }}$ & & $\begin{array}{l}\text { 2nd } \\
\text { vs 1st }\end{array}$ & $\begin{array}{l}\text { 3rd } \\
\text { vs }\end{array}$ & $\begin{array}{l}\text { 3rd vs. } \\
\text { 2nd }\end{array}$ \\
\hline $\mathrm{n}(\%)$ & $\begin{array}{l}\mathrm{Cl}_{95} \\
\text { for } \\
\%^{2}\end{array}$ & $n(\%)$ & $\begin{array}{l}\mathrm{Cl}_{95} \\
\text { for } \\
\%^{2}\end{array}$ & $n(\%)$ & $\begin{array}{l}\mathrm{Cl}_{95} \\
\text { for } \\
\%^{2}\end{array}$ & & 1st & \\
\hline
\end{tabular}

\section{LMR}

\begin{tabular}{|c|c|c|c|c|c|c|c|c|c|}
\hline LMR-high (>2.6) & $\begin{array}{l}34 \\
(56.7)\end{array}$ & $\begin{array}{l}43.2- \\
69.4\end{array}$ & $\begin{array}{l}35 \\
(58.3)\end{array}$ & $\begin{array}{l}44.5- \\
70.9\end{array}$ & $\begin{array}{l}33 \\
(55.0)\end{array}$ & $\begin{array}{l}41.6- \\
67.9\end{array}$ & \multirow[t]{2}{*}{$>0.999$} & \multirow[t]{2}{*}{0.791} & \multirow[t]{2}{*}{0.607} \\
\hline LMR-Iow ( $\leq 2.6)$ & $\begin{array}{l}26 \\
(43.3)\end{array}$ & $\begin{array}{l}30.6- \\
56.8\end{array}$ & $\begin{array}{l}25 \\
(41.7)\end{array}$ & $\begin{array}{l}29.1- \\
55.1\end{array}$ & $\begin{array}{l}27 \\
(45.0)\end{array}$ & $\begin{array}{l}32.1- \\
58.4\end{array}$ & & & \\
\hline $\begin{array}{l}\text { "True LMR-high / } \\
\text { LMR-low" - }\end{array}$ & $x$ & $x$ & $\begin{array}{l}49 \\
(81.7)\end{array}$ & $\begin{array}{l}69.6- \\
90.5\end{array}$ & $\begin{array}{l}41 \\
(68.3)\end{array}$ & $\begin{array}{l}55.0- \\
79.7\end{array}$ & $x$ & $x$ & 0.804 \\
\hline \multicolumn{10}{|l|}{$\begin{array}{l}\text { patients who } \\
\text { remained in the } \\
\text { same group }\end{array}$} \\
\hline $\begin{array}{l}\text { (LMR-high or LMR- } \\
\text { low) after the } 2^{\text {nd }} / \\
3^{\text {rd }} \text { measurement }\end{array}$ & & & & & & & & & \\
\hline
\end{tabular}

\section{NLR}

$\begin{array}{llllllllll}\text { NLR-high }(\geq 3.0) & 23 & 26.1- & 27 & 32.1- & 21 & 23.1- & 0.455 & 0.754 & 0.146\end{array}$

$\begin{array}{lllllll}\text { NLR-low }(<3.0) & 37 & 48.2- & 33 & 41.6- & 39 & 51.6- \\ & (61.7) & 73.9 & (55.0) & 67.9 & (65.0) & 76.9\end{array}$

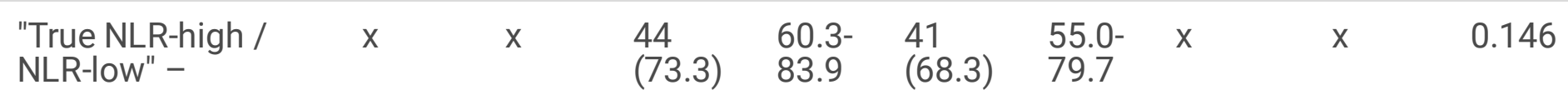

NLR-low" -

patients who remained in the same group

(NLR-high or NLRlow) after the $2^{\text {nd }} /$ $3^{\text {rd }}$ measurement

\section{PLR}

\begin{tabular}{|c|c|c|c|c|c|c|c|c|c|}
\hline PLR-high ( $\geq 150)$ & $\begin{array}{l}29 \\
(48.3)\end{array}$ & $\begin{array}{l}35.2- \\
61.6\end{array}$ & $\begin{array}{l}24 \\
(40.0)\end{array}$ & $\begin{array}{l}27.6- \\
53.5\end{array}$ & $\begin{array}{l}26 \\
(43.3)\end{array}$ & $\begin{array}{l}30.6- \\
56.8\end{array}$ & 0.180 & 0.581 & 0.581 \\
\hline PLR-low $(<150)$ & $\begin{array}{l}31 \\
(51.7)\end{array}$ & $\begin{array}{l}38.4- \\
64.8\end{array}$ & $\begin{array}{l}36 \\
(60.0)\end{array}$ & $\begin{array}{l}46.5- \\
72.4\end{array}$ & $\begin{array}{l}34 \\
(56.7)\end{array}$ & $\begin{array}{l}43.2- \\
69.4\end{array}$ & & & \\
\hline $\begin{array}{l}\text { "True PLR-high / } \\
\text { PLR-low" - }\end{array}$ & $x$ & $x$ & $\begin{array}{l}47 \\
(78.3)\end{array}$ & $\begin{array}{l}65.8^{-} \\
87.9\end{array}$ & $\begin{array}{l}42 \\
(70.0)\end{array}$ & $\begin{array}{l}56.8- \\
81.2\end{array}$ & $x$ & $x$ & $>0.999$ \\
\hline
\end{tabular}


patients who

remained in the

same group

(PLR-high or PLR-

low) after the $2^{\text {nd }} /$

$3^{\text {rd }}$ measurement

${ }^{1}$ Comparison between measurements with McNemar test

2 95\% confidence interval $(\mathrm{Cl})$ for proportion based on binomial exact calculation

Over half of the patients - $56.7 \%(95 \% \mathrm{Cl}, 43.2-69.4 \%)$ were classified as LMR-high; $61.7 \%(95 \% \mathrm{Cl}, 48.2-$ $73.9 \%)$ and $51.7 \%(95 \% \mathrm{Cl}, 38.4-64.8 \%)$ of patients were assigned to NLR-low and PLR-low group accordingly. After the second measurement $81.7 \%(95 \% \mathrm{Cl}, 69.6-90.5 \%)$ of patients belonged to the same group (LMR-high or LMR-low). In terms of NLR and PLR there was 73.3\% (95\% $\mathrm{Cl}, 60.3-83.9 \%)$ and $78.3 \%$ $(95 \% \mathrm{Cl}, 65.8-87.9 \%)$ of patients in the same group, respectively. Interestingly, after three measurements the percentage of patients who stayed in the same group ("true LMR, NLR, PLR-high or low") was almost identical: $68.3 \%$ (95\% Cl, 55.0-79.7\%) for LMR and NLR and 70.0\% (95\% Cl, 56.8-81.2\%) for PLR. For LMR, NLR and PLR there were no significant changes in percentage of patients classified as low/high between all 3 measurements $p>0.05$ in all comparisons).

Mean percentage change between the third and the first measurement of lymphocytes, monocytes, neutrophils and platelets count ranged from $-5.59 \%$ to $4.76 \%$ and the standard error from 2.0 to 3.9 (table 4.; fig. 1).

\section{Table 4. Calculation as $\%$ change $3^{\text {rd }}$ measurement vs $1^{\text {st }}$ measurement}

\begin{tabular}{llllllll}
$\begin{array}{l}\% \\
\text { change }\end{array}$ & $\mathrm{n}$ & Mean & $\begin{array}{l}\text { Standard } \\
\text { deviation }\end{array}$ & $\begin{array}{l}\text { Standard } \\
\text { error }\end{array}$ & Median & Minimum & Maximum \\
\hline $\mathrm{L}$ & 60 & 4,76 & 30,23 & 3,9 & 0,75 & $-60,61$ & 92,86 \\
\hline M & 60 & 3,88 & 24,39 & 3,1 & 4,78 & $-40,00$ & 85,71 \\
\hline N & 60 & $-5,59$ & 20,57 & 2,7 & $-8,20$ & $-47,70$ & 43,66 \\
\hline WBC & 60 & $-2,39$ & 17,28 & 2,2 & $-3,86$ & $-39,78$ & 42,12 \\
\hline PLT & 60 & 1,29 & 15,30 & 2,0 & $-0,70$ & $-29,32$ & 44,60
\end{tabular}

Cohen's Kappa statistic for the extent of agreement between the 1st and the 2nd measurement for LMR was $\mathrm{K}=0.59(95 \% \mathrm{Cl}, 0.39-0.79), \mathrm{p}<0.001$. For NLR the Kappa was $\mathrm{K}=0.45(95 \% \mathrm{Cl}, 0.22-0.68), \mathrm{p}<0.001$ and for PLR $\mathrm{K}=0.53(95 \% \mathrm{Cl}, 0.32-0.75), \mathrm{p}<0.001$, meaning in all cases a moderate agreement between both measurements. 
If LMR at the first time was out of the range of 2.2-3.0 (+/- 0.4 from the cut-off) the risk of misclassification in the second measurement, defined as an affiliation to a different (high or low) group than initially, dropped to $5.0 \%$ (95\% $\mathrm{Cl}, 1.0-13.9 \%)$. In case of NLR, when outside of the range of 2.5-3.5 $(+/-0.5)$ in the first test, it was $8.3 \%(95 \% \mathrm{Cl}, 2.8-18.4 \%)$ and in case of PLR outside of the range of $125-$ 175 (+/- 25) 10.0\% (95\% Cl, 3.8-20.5\%). The distribution of misclassifications based on initial values of SIR markers are shown in fig. 2.

The analysis of correlation between the first and the third measurement of LMR, NLR and PLR was conducted. LMR values were correlated with the coefficient of $0.776(p<0.00001)$. NLR and PLR were correlated with the coefficient of $0.696(p<0.000089)$ and $0.751(p<0.00001)$ (appendix fig. 2.).

\section{Discussion}

LMR, NLR and PLR are thoroughly investigated biomarkers with high prognostic and potential predictive value in many malignancies. However, they still lack proper validation and the number of studies assessing their reproducibility is very limited. To the best of our knowledge, our study is the first to directly investigate this subject in prospectively enrolled cohort. The reference and cut-off values of SIR markers are not well-established. Based on analyses of ostensibly healthy populations average value of LMR, NLR and PLR may differ depending on race, sex and age. Mean values of LMR in healthy individuals were significantly higher and mean values of NLR and PLR lower in comparison to our results [12-14]. Our findings suggest that all three SIR markers are reproducible in rectal cancer patients. These results are in line with our previous retrospective study of reproducibility of LMR in patients with LARC where two peripheral blood tests within 5 weeks prior to anti-cancer therapy were performed. LMRs calculated at two time-points were correlated with the coefficient of $0.588(p<0.005)$. Patients were allocated into LMR-high and LMR-low groups using the cut-off value of 2.6. The same percentage of patients (18\%) as in the current study had not been re-assigned to the LMR group in the second test ( $95 \% \mathrm{Cl}, 8.6-31.4 \%)$. The chance for misclassification was 7.5\% (95\% Cl, 1.6-20.4\%) if LMR in the first measurement was outside of the range of $2.2-3.0$ compared to $5 \%(95 \% \mathrm{Cl}, 1.0-13.9 \%)$ in our current study [11]. The stability of NLR over time, up to 100 days, was demonstrated in cardiac surgery patients, it was not confirmed in cancer population, though [15]. No other studies investigating the reproducibility of SIR markers have been found in the literature. As more research of cancer-related inflammation (CRI) indices is still needed in order to apply them in clinical practice, better understanding of CRI phenomena is of the essence.

The relationship between cancer and inflammation has been investigated since the 19th century when Virchow first observed that cancer tends to originate from chronically inflamed sites [16]. Through recruitment of inflammatory cells and cytokines, production of reactive oxygen species and inhibiting repair programs, inflammation promotes uncontrolled proliferation of defective cells and potentiates neoplastic risk. Inflammatory cells are abundant in tumor's microenvironment [17]. They reflect not only a reaction of the host towards tumor, but also, as a product of cancer-related cells, tumor's predisposition towards invading and suppressing the immune system [18]. Lymphocytes which count is assumed to reflect systemic inflammatory response, by inducing the production of anti-tumor cytokines and cytotoxic 
activity suppress cancer's proliferation and spread [19]. Correlation between lymphopenia and poor prognosis has been demonstrated in many malignancies [20]. Monocytes, on the contrary, are proved to contribute to tumor's progression and metastatic activity [21]. Tumor-associated macrophages (TAMs) are monocyte-derived macrophages abundantly present within infiltrates of the cancer tissue. TAMs potentiate tumor's progression by producing growth factors, cytokines and proteases. Moreover, TAMs secrete II-10 which suppresses anti-tumoral CD4+ T cells activation [22]. High peripheral monocyte count has a negative impact on OS and PFS in solid tumors [23]. Combining the effect of lymphocytes and monocytes on immunological system led to an introduction of lymphocyte-to-monocyte ratio (LMR) which is one of the most investigated SIR marker with potent prognostic value. Studies show that low and high LMR is associated with poor and favorable prognosis respectively. This pattern is consistently confirmed in various malignancies [5]. In CRC the prognostic value of LMR is well-documented in both early, locally advanced and metastatic stages [24]. Low pre-treatment LMR was proved to predict a significantly worse prognosis in patients with LARC following TME [25]. It predicts a pathological response to neoadjuvant chemoradiotherapy [26]. LMR was also investigated as a predictive factor for a neo-adjuvant radiation regimen with promising results [10]. An association between the biomarker and tumor location (sidedness), metabolic parameters of baseline ${ }^{18} \mathrm{~F}-\mathrm{FDG}$ PET/CT or postoperative infectious complications in patients with CRC have been demonstrated in recent years [27-29]. Neutrocytes and thrombocytes are both negative prognostic factors in cancer patients [30, 31]. Neutrophils, accounting for $50-70 \%$ of leukocytes, play a central role in CRI. Releasing reactive oxygen and nitrogen species which damage DNA they take a substantial part in cancer initiation [32]. Tumor progression is boosted by neutrophil-derived chemokines and cytokines mediating the process of angiogenesis [33]. Neutrocytes take part in suppressing lymphocyte T proliferation, reducing the antitumoral effect of NK-cells and promoting metastatic spread [34, 35]. Similarly, platelets by releasing cytokines and growth factors contribute to carcinogenesis. There is a substantial interaction between thrombocyte activation and cancer progression. Tumor cells produce cytokines such as IL-6 which stimulate thrombocytosis. In turn thrombocytes promote further tumor growth leading to an even more intensive stimulation and activation of platelets [36]. The association between thrombocytosis and cancer is well-documented and high platelet count emerges as an important marker of cancer [37]. NLR and PLR have been proved to have negative prognostic value in solid tumors [38,39]. Their prognostic role have been demonstrated in non-oncological medical conditions such as sepsis, pulmonary embolism or COVID-19 pneumonia [40-42]. An increasing number of studies indicate predictive properties of these hematological indices e.g. in breast cancer low pretreatment values of NLR and PLR were proved to be associated with higher complete response rate to neoadjuvant chemotherapy [43]. Pre-treatment NLR and PLR may be helpful in identifying patients who would be most appropriate for immunotherapy as a second line treatment in non-small cell lung cancer [44]. Similarly to LMR an association was found between PET-CT metabolic parameters and both NLR and PLR $[45,46]$. NLR and PLR may be useful in predicting lymph node positivity and recurrences after surgery in gastrointestinal cancers [47].

All three SIR markers have strong prognostic value in cancer and their predictive role is heavily investigated. Results of our study confirm that LMR, NLR and PLR are good candidates for biomarkers 
given their accessibility, reproducibility and low cost. A vast potential for use in clinical practice is evident and efforts to include them into existing risk scoring systems or use them as parts of novel ones are already on the way and the results are promising $[48,49]$.

There are several limitations concerning our study: a) a relatively small group of patients; b) possibility of undocumented patients' medical conditions that might have affected SIR markers count such as infection, exacerbation of chronic renal, hepatic or cardiac disease etc.; c) homogeneity of studied population which consisted entirely of citizens of Poland of Caucasian ethnicity. More studies which would include larger, mixed populations are required to confirm our results. Despite limitations our study concentrates on the subject hardly present in the literature which is crucial for proper determination of reliability of LMR, NLR and PLR as prognostic markers and their application in clinical practice.

\section{Conclusions}

LMR, NLR and PLR are easily accessible and reproducible parameters. Considering their well-proved high prognostic value they have potential to become new biomarkers for patients with colorectal cancer and other malignancies. More studies are needed to improve their validation and enable broader application in clinical practice.

\section{Abbreviations}

LMR, lymphocyte-to-monocyte ratio; NLR, neutrophil-to-lymphocyte ratio; PLR, platelet-to-lymphocyte ratio; $\mathrm{CRI}$, cancer-related inflammation; SIR, systemic inflammatory response

\section{Declarations}

\section{Acknowledgments}

This research did not receive any specific grant from funding agencies in the public, commercial, or notfor-profit sectors.

\section{Competing interests}

The author(s) declare no competing interests.

Author Contributions: Conceptualization, C. G. and L. W.; methodology, C. G. and L. W.; software, W. M.; validation, L. W. and W. M.; formal analysis, C. G.; investigation, C. G.; resources, C. G.; data curation, C. G.; writing-original draft preparation, C. G.; writing-review and editing, C. G. and L. W.; visualization, C. G.; supervision, L. W.; project administration, C. G. All authors have read and agreed to the published version of the manuscript.

Data Availability Statement: The data presented in this study are available on request from the corresponding author. The data are not publicly available due to medical data privacy issues. 
Funding: This research received no external funding.

Institutional Review Board Statement: The study conformed to the provisions of the Declaration of Helsinki and was approved by the Ethics Committee of Maria Skłodowska-Curie National Research Institute of Oncology in Warsaw (81/2017)

\section{References}

1. Glynne-Jones, R., et al., Rectal cancer: ESMO Clinical Practice Guidelines for diagnosis, treatment and follow-up. Ann Oncol, 2017. 28(suppl_4): p. iv22-iv40.

2. Brierley, J., et al., TNM classification of malignant tumours. 2017.

3. Bahadoer, R.R., et al., Short-course radiotherapy followed by chemotherapy before total mesorectal excision (TME) versus preoperative chemoradiotherapy, TME, and optional adjuvant chemotherapy in locally advanced rectal cancer (RAPIDO): a randomised, open-label, phase 3 trial. Lancet Oncol, 2021. 22(1): p. 29-42.

4. Zhou, X., et al., Prognostic value of PLR in various cancers: a meta-analysis. PLoS One, 2014. 9(6): p. e101119.

5. Nishijima, T.F., et al., Prognostic value of lymphocyte-to-monocyte ratio in patients with solid tumors: A systematic review and meta-analysis. Cancer Treat Rev, 2015. 41(10): p. 971-8.

6. Cupp, M.A., et al., Neutrophil to lymphocyte ratio and cancer prognosis: an umbrella review of systematic reviews and meta-analyses of observational studies. BMC Med, 2020. 18(1): p. 360.

7. Song, W., et al., Prognostic value of the lymphocyte monocyte ratio in patients with colorectal cancer: A meta-analysis. Medicine, 2016. 95(49).

8. Li, H., Y. Zhao, and F. Zheng, Prognostic significance of elevated preoperative neutrophil-tolymphocyte ratio for patients with colorectal cancer undergoing curative surgery: A meta-analysis. Medicine, 2019. 98(3): p. e14126-e14126.

9. Chen, N., et al., Increased platelet-lymphocyte ratio closely relates to inferior clinical features and worse long-term survival in both resected and metastatic colorectal cancer: an updated systematic review and meta-analysis of 24 studies. Oncotarget, 2017. 8(19): p. 32356-32369.

10. Winiarek, M., et al., Lymphocyte-to-monocyte ratio (LMR) is prognostic factor for selection of neoadjuvant treatment in locally advanced rectal cancer patients: Sub-set analysis of Polish-2 study. Annals of Oncology, 2017. 28: p. iii124-iii125.

11. Gawiński, C., et al., Reproducibility of pretreatment lymphocyte-to-monocyte ratio (LMR) in rectal cancer. 2018. 36(4_suppl): p. 715-715.

12. Meng, X., et al., Determinant roles of gender and age on SII, PLR, NLR, LMR and MLR and their reference intervals defining in Henan, China: A posteriori and big-data-based. J Clin Lab Anal, 2018. 32(2). 
13. Azab, B., M. Camacho-Rivera, and E. Taioli, Average values and racial differences of neutrophil lymphocyte ratio among a nationally representative sample of United States subjects. PloS one, 2014. 9(11): p. e112361-e112361.

14. Lee, J.S., et al., Reference values of neutrophil-lymphocyte ratio, lymphocyte-monocyte ratio, plateletlymphocyte ratio, and mean platelet volume in healthy adults in South Korea. Medicine, 2018. 97(26): p. e11138-e11138.

15. Green, J., et al., Stability across time of the neutrophil-lymphocyte and lymphocyte-neutrophil ratios and associations with outcomes in cardiac surgery patients. Journal of cardiothoracic surgery, 2019. 14(1): p. 164-164.

16. Virchow, R., Cellular pathology. As based upon physiological and pathological histology. Lecture XVI-Atheromatous affection of arteries. 1858. Nutr Rev, 1989. 47(1): p. 23-5.

17. Zhang, S., et al., Interplay between inflammatory tumor microenvironment and cancer stem cells. Oncol Lett, 2018. 16(1): p. 679-686.

18. Mantovani, A., et al., Cancer-related inflammation. Nature, 2008. 454(7203): p. 436-44.

19. Terzić, J., et al., Inflammation and colon cancer. Gastroenterology, 2010. 138(6): p. 2101-2114.e5.

20. Ray-Coquard, I., et al., Lymphopenia as a prognostic factor for overall survival in advanced carcinomas, sarcomas, and lymphomas. Cancer Res, 2009. 69(13): p. 5383-91.

21. Joyce, J.A. and J.W. Pollard, Microenvironmental regulation of metastasis. Nat Rev Cancer, 2009. 9(4): p. 239-52.

22. Coussens, L.M. and Z. Werb, Inflammation and cancer. Nature, 2002. 420(6917): p. 860-867.

23. Wen, S., et al., Elevated peripheral absolute monocyte count related to clinicopathological features and poor prognosis in solid tumors: Systematic review, meta-analysis, and meta-regression. 2021. 10(5): p. 1690-1714.

24. Tan, D., et al., Prognostic significance of lymphocyte to monocyte ratio in colorectal cancer: A metaanalysis. International Journal of Surgery, 2018. 55: p. 128-138.

25. Xiao, W.W., et al., A Low Lymphocyte-to-Monocyte Ratio Predicts Unfavorable Prognosis in Pathological T3NO Rectal Cancer Patients Following Total Mesorectal Excision. J Cancer, 2015. 6(7): p. 616-22.

26. Li, A., et al., Pretreatment blood biomarkers predict pathologic responses to neo-CRT in patients with locally advanced rectal cancer. Future Oncol, 2019. 15(28): p. 3233-3242.

27. Patel, M., et al., The relationship between tumor location, tumor microenvironment, systemic inflammation, and cancer-specific survival in patients undergoing surgery for colon cancer. Journal of Clinical Oncology, 2017. 35(4_suppl): p. 689-689.

28. Xu, J., et al., The significant value of predicting prognosis in patients with colorectal cancer using (18)F-FDG PET metabolic parameters of primary tumors and hematological parameters. Ann Nucl Med, 2019. 33(1): p. 32-38. 
29. Kamonvarapitak, T., et al., Preoperative lymphocyte-to-monocyte ratio predicts postoperative infectious complications after laparoscopic colorectal cancer surgery. Int J Clin Oncol, 2020. 25(4): p. 633-640.

30. Ocana, A., et al., Neutrophils in cancer: prognostic role and therapeutic strategies. Mol Cancer, 2017. 16(1): p. 137.

31. Zhang, X., et al., The clinicopathological and prognostic role of thrombocytosis in patients with cancer: A meta-analysis. Oncology letters, 2017. 13(6): p. 5002-5008.

32. Antonio, N., et al., The wound inflammatory response exacerbates growth of pre-neoplastic cells and progression to cancer. Embo j, 2015. 34(17): p. 2219-36.

33. Tazzyman, S., C.E. Lewis, and C. Murdoch, Neutrophils: key mediators of tumour angiogenesis. Int J Exp Pathol, 2009. 90(3): p. 222-31.

34. Zhang, X. and W. Xu, Neutrophils diminish T-cell immunity to foster gastric cancer progression: the role of GM-CSF/PD-L 1/PD-1 signalling pathway. Gut, 2017. 66(11): p. 1878-1880.

35. Spiegel, A., et al., Neutrophils Suppress Intraluminal NK Cell-Mediated Tumor Cell Clearance and Enhance Extravasation of Disseminated Carcinoma Cells. Cancer Discov, 2016. 6(6): p. 630-49.

36. Lin, R.J., V. Afshar-Kharghan, and A.I. Schafer, Paraneoplastic thrombocytosis: the secrets of tumor self-promotion. Blood, 2014. 124(2): p. 184-7.

37. Bailey, S.E., et al., Clinical relevance of thrombocytosis in primary care: a prospective cohort study of cancer incidence using English electronic medical records and cancer registry data. Br J Gen Pract, 2017. 67(659): p. e405-e413.

38. Templeton, A.J., et al., Prognostic role of neutrophil-to-lymphocyte ratio in solid tumors: a systematic review and meta-analysis. J Natl Cancer Inst, 2014. 106(6): p. dju124.

39. Templeton, A.J., et al., Prognostic role of platelet to lymphocyte ratio in solid tumors: a systematic review and meta-analysis. Cancer Epidemiol Biomarkers Prev, 2014. 23(7): p. 1204-12.

40. Yang, A.P., et al., The diagnostic and predictive role of NLR, $d-N L R$ and PLR in COVID-19 patients. Int Immunopharmacol, 2020. 84: p. 106504.

41. Wang, Q., et al., Prognostic value of neutrophil-to-lymphocyte ratio and platelet-to-lymphocyte ratio in acute pulmonary embolism: a systematic review and meta-analysis. Int Angiol, 2018. 37(1): p. 4-11.

42. Huang, Z., et al., Prognostic value of neutrophil-to-lymphocyte ratio in sepsis: A meta-analysis. Am J Emerg Med, 2020. 38(3): p. 641-647.

43. Graziano, V., et al., Combination of peripheral neutrophil-to-lymphocyte ratio and platelet-tolymphocyte ratio is predictive of pathological complete response after neoadjuvant chemotherapy in breast cancer patients. Breast, 2019. 44: p. 33-38.

44. Petrova, M.P., et al., Neutrophil to lymphocyte ratio as a potential predictive marker for treatment with pembrolizumab as a second line treatment in patients with non-small cell lung cancer. Biosci Trends, 2020. 14(1): p. 48-55. 
45. Mirili, C., et al., Prognostic significance of neutrophil/lymphocyte ratio (NLR) and correlation with PET-CT metabolic parameters in small cell lung cancer (SCLC). Int J Clin Oncol, 2019. 24(2): p. 168178.

46. Fujii, T., et al., Relationship Between FDG Uptake and the Platelet/lymphocyte Ratio in Patients With Breast Invasive Ductal Cancer. In Vivo, 2020. 34(3): p. 1365-1369.

47. Nora, I., et al., The accuracy of neutrophil to lymphocyte ratio and platelet to lymphocyte ratio as a marker for gastrointestinal malignancies. Journal of gastrointestinal oncology, 2018. 9(5): p. 972978.

48. Hirahara, N., et al., A Novel Prognostic Scoring System Using Inflammatory Response Biomarkers for Esophageal Squamous Cell Carcinoma. World J Surg, 2018. 42(1): p. 172-184.

49. Wang, Y., et al., Prognostic value of a novel scoring system using inflammatory response biomarkers in non-small cell lung cancer: A retrospective study. Thoracic cancer, 2019. 10(6): p. 1402-1411.

\section{Figures}

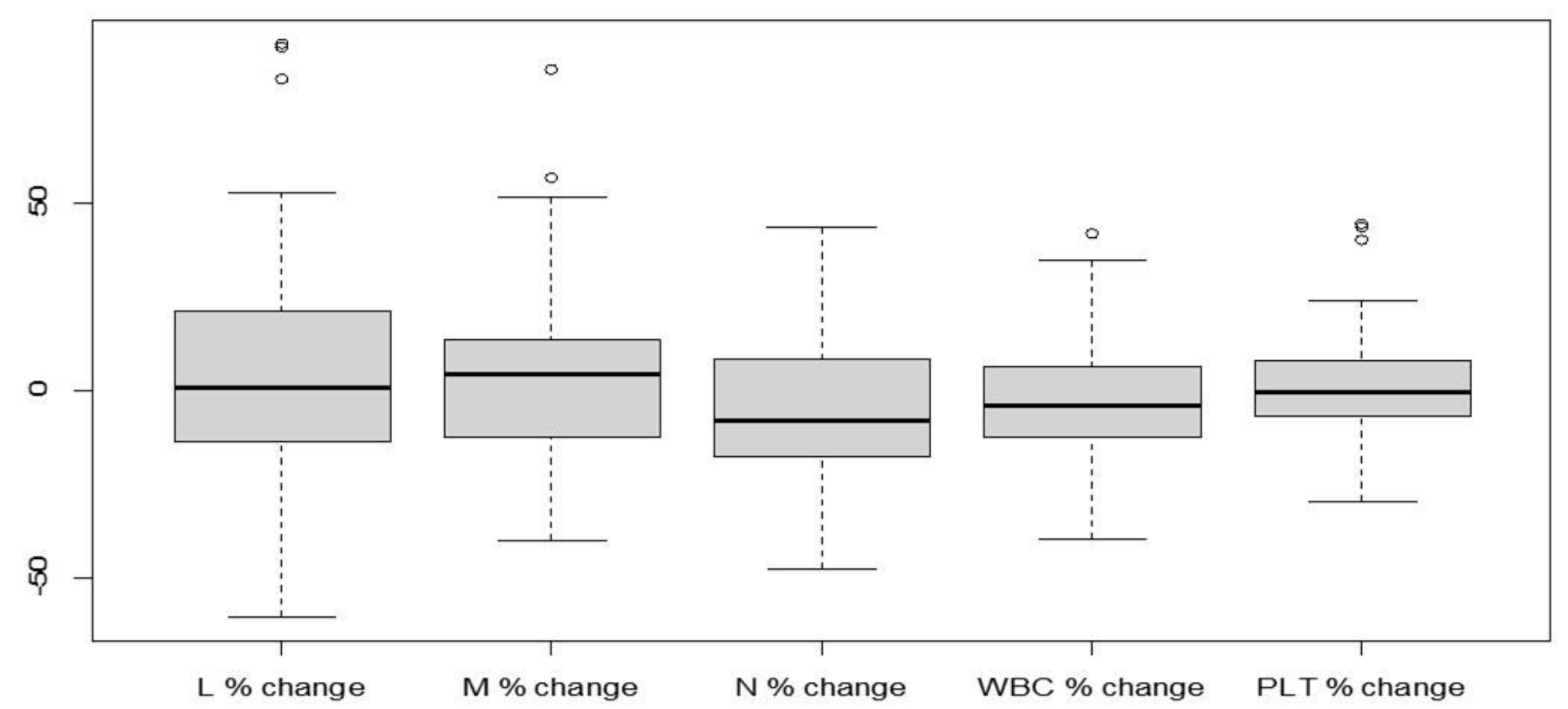

\section{Figure 1}

Boxplot of $\%$ changes between $3^{\text {rd }}$ and $1^{\text {st }}$ measurement 

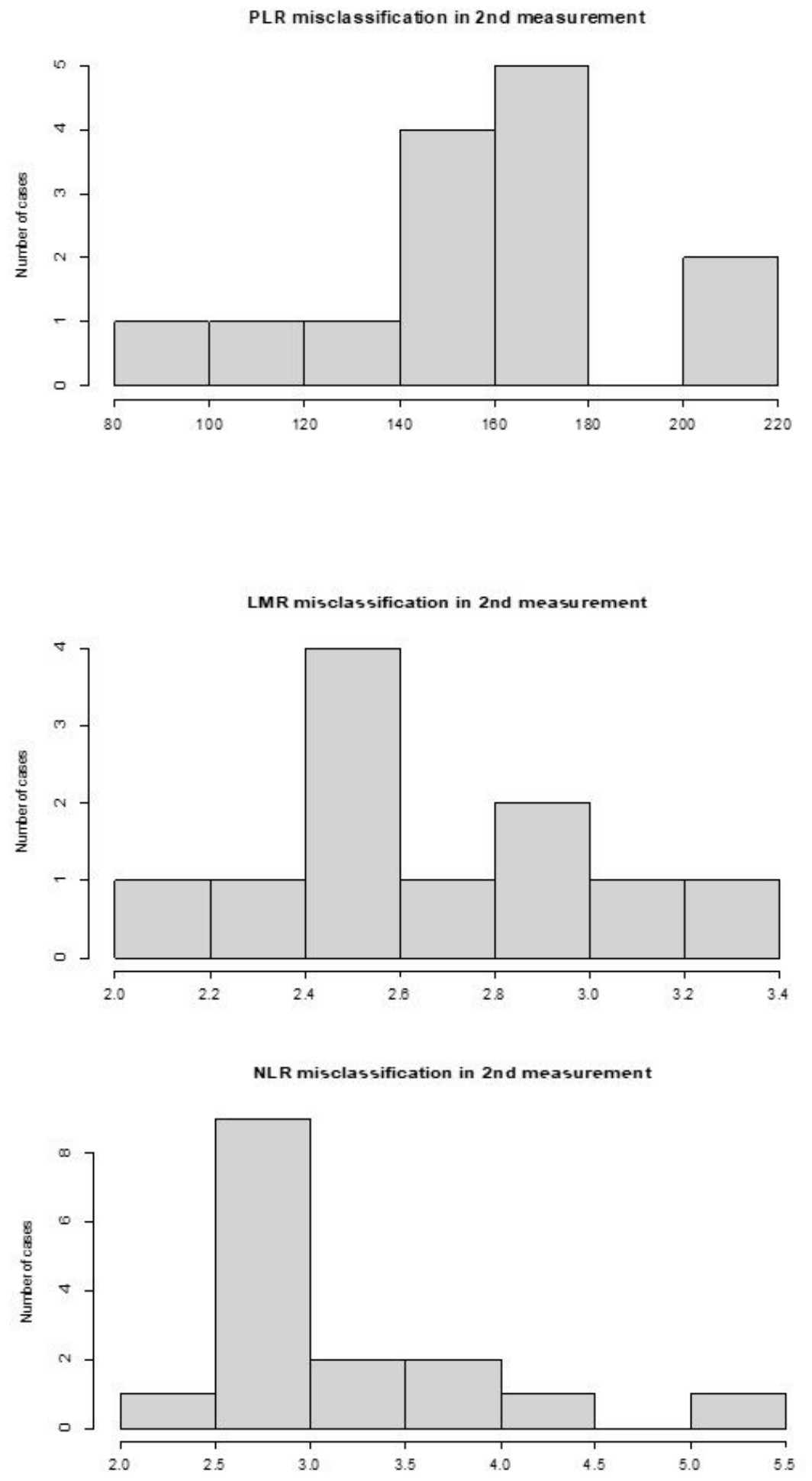

\section{Figure 2}

Number of misclassifications in the $2^{\text {nd }}$ measurement (LMR,NLR,PLR-high/low) based on the value of LMR, NLR and PLR.

\section{Supplementary Files}


This is a list of supplementary files associated with this preprint. Click to download.

- SIRreproducibilityappendixSupplementaryfile.docx 